Amazonía Peruana, Volumen XVI, No 32, 2019; p.p 257-270

\title{
CRÓNICAS
}

\section{Autos de los indios chunchos remitidos por el Gral. Marqués de Menahermosa por sospecha de ser espías del rebelde Juan Santos Atahuallpa.}

\section{Introducción}

Fernando Santos Granero

Smithsonian Tropical Research Institute

El manuscrito que se trascribe a continuación se encuentra en la Sección Colonial del Archivo General de la Nación bajo la Signatura GO BI BI1 028, 152. Data de 1746, cuatro años después de iniciada la sublevación multiétnica inspirada por el discurso mesiánico y anticolonial del líder andino Juan Santos Atahuallpa que arrasó la Selva Central. Ese mismo año, el nuevo virrey, Don José Manso de Velasco, le encargó la represión del levantamiento al Gral. Don José de Llamas y Estrada, Marqués de Menahermosa (1687-1772), con la esperanza de que éste lograse lo que por años no había conseguido el corregidor de Tarma, Don Alfonso de Santa y Ortega. En marzo de 1746, el Gral. Llamas entró al valle de Huancabamba al mando de doscientos hombres de armas y trescientos cargadores, mientras que el Gobernador de Fronteras, Don Benito Troncoso, entraba por el valle de Chanchamayo con ciento cincuenta hombres de armas y doscientos de carga. La expedición fue un fracaso y si no terminó en una masacre fue porque Juan Santos se encontraba retirado tierra adentro. El único logro del Gral. Llamas fue la toma del pueblo de Huancabamba, abandonado desde hacía varios años por los misioneros franciscanos y las autoridades coloniales, y la captura de dieciséis prisioneros entre hombres, mujeres y niños a los cuales remitió inmediatamente a la ciudad de Tarma acusados de ser espías. Poco después, el virrey ordenó que los prisioneros fueran trasladados a la Real Cárcel de Corte de Lima e interrogados por Dn. Manuel Antonio de Borda, Alcalde del Crimen y Juez de Provincia de la Real Audiencia de Lima. Los presos fueron remitidos a Lima el 14 de mayo de 1746. Solo llegaron quince, ya que una de las cautivas escapó estando en Tarma.

En cumplimiento de la orden del virrey, el 23 de mayo de 1746, Borda procedió a interrogar a los prisioneros en compañía del escribano Agustín Jerónimo de Portalanza y del intérprete general de los naturales de la Real Audiencia, Don 
Joseph Caiotopa Tito Athuchy Uscamayta. El grupo estaba compuesto por tres hombres, seis mujeres y seis niños, incluido un bebé nacido durante el traslado de los presos. Dado que Huancabamba estaba en pleno territorio yánesha, es de suponer que los presos pertenecían a este grupo étnico. Trece de los prisioneros estaban emparentados entre sí, formando cinco pequeños grupos familiares: 1 . Petrona de 60 años y su hijo Pedro Alcantara (20); 2. Francisco Solano de 50 años, con su hija Juana Petrona (20) y sus nietas María Isabel (8) y María Dominga (3); 3. María Bernarda de 34 años y su hija Petrona Margarita (4); 4. María Josepha de 20 años y su hija Martina Sebastiana (infante); y 5. Juana Narcisa de 18 años, su hermana María Espíritu o Juana Espíritu Santo (6), y su hija recién nacida María Encarnación. Adicionalmente, había dos individuos no relacionados: Matheo de 35 años y María Dominga Asencio de 17.

Llama la atención de la composición de este grupo el bajo número de hombres y el alto porcentaje de viudas -cuatro de las seis mujeres lo eran-, lo que sugiere alternativamente que los hombres lograron escapar cuando las tropas del Gral. Llamas atacaron Huancabamba, que habían abandonado el pueblo para unirse a las fuerzas rebeldes, o que fueron diezmados tras años de enfrentamientos con los rebeldes. Esto último es lo más probable, ya que María Bernarda declara ser viuda de Dn. Bernardo Tigsiguaina, curaca de Guancabamba, quien fuera asesinado por los "indios Aucas" del Cerro de la Sal en 1742, al inicio del levantamiento.

El objetivo del interrogatorio era determinar si los prisioneros actuaban como espías a favor de Juan Santos Atahuallpa, a quien en este manuscrito se llama Indio Auca, Indio Bravo o Indio rebelde, y si los habitantes de Huancabamba y los de los pueblos andinos fronterizos, tales como Carhuamayo, Quiparacra, Ninacaca, Paucartambo, Reyes, Vico, Pasco y Tarma, pasaban información o comerciaban con los sublevados. Dado que solo Matheo y Juana Petrona sabían hablar castellano y que solo María Bernarda sabía hablar quechua, es de suponer que el interrogatorio se llevó a cabo mayormente en yánesha.

Las respuestas de los prisioneros son muy uniformes. Todos declaran no ser espías. Insisten en que son cristianos y no "aucas" como los rebeldes -término que en este contexto parece ser sinónimo de "infieles" más que de "salvajes". Afirman no tener comunicación o comerciar con los rebeldes. Y dicen que los rebeldes nunca pasan a Huancabamba porque "no pueden ver" a los cristianos. Dicen lo mismo de los comerciantes mestizos y españoles que bajaban a Huancabamba a comprarles productos tropicales, afirmando que éstos nunca pasan a la otra banda del río Huancabamba, el cual aparece como la frontera natural entre los indígenas rebeldes y aquellos afectos a los españoles. Esto bien puede haber sido verdad. El valle de Huancabamba fue una de las primeras zonas de la Selva Central en ser evangelizadas. En 1576, el mercedario Fr. Diego de Porres, entrando desde Huánuco encontró dos parcialidades -Oxamarcas y Pilcozones-, a las que reasentó en el valle de Huancabamba. Estas parcialidades pertenecían, con toda probabilidad, al pueblo 
yánesha. Desde entonces, esta zona estuvo en contacto intermitente con la esfera colonial, mayormente bajo la tutela de los misioneros franciscanos. Sabemos también que en 1743 las tropas de Juan Santos saquearon Huancabamba, lo que indica que sus habitantes se habían negado a unirse a la rebelión. Es posible que haya sido en dicha ocasión que Bernardo Tigsihuaina, curaca de Huancabamba, fuera asesinado por los rebeldes.

No deja de llamar la atención, sin embargo, que los interrogados insistan tanto en que ni ellos ni los habitantes de los pueblos andinos fronterizos tenían comunicación alguna con los rebeldes. Igualmente, llama la atención que afirmen no recordar los nombres de los mercaderes andinos con los que comerciaban y que los conocían solo "de vista". Esta reticencia sugiere que los prisioneros eran conscientes de las graves consecuencias que podría acarrearles a ellos, a sus familiares y a sus socios comerciales el ser acusados de espías y se cuidaban mucho de proporcionar cualquier información que pudiera incriminarlos. A pesar de que la Audiencia dictaminó que los prisioneros no eran culpables del cargo de espionaje, ordenó que estos no fueran regresados a Huancabamba, sino repartidos en los pueblos fronterizos para que no estuviesen expuestos al "peligro de comunicación con los Ynfieles".

Este documento es importante para entender la compleja dinámica entre los diversos actores sociales que se vieron enfrentados en el contexto de la sublevación de Juan Santos Atahuallpa. Un análisis comparativo del mismo con otros similares recogidos por Francisco Loayza en "Juan Santos, el invencible" podría arrojar más luz sobre las divisiones existentes tanto entre los indígenas amazónicos como entre los andinos en lo que respecta a su apoyo a la rebelión. 
Autos de los indios chunchos remitidos por el Gral. Marqués de Menahermosa por sospecha de ser espías del rebelde Juan Santos Atahuallpa; Lima, 25 de mayo de 1746. [AGN: GO BI BI1 028, 152]

[f. 1] Exmo. Sr. Dn. Joseph Manso de Velasco

Exmo. Sr:

Quando llegue a este Pueblo con el horden de mi Gral. para despachar los chunchos a V. Exa. halle depositadas en casa de Dn. Joseph Bermudes dos chunchas grandes y tres muchachas y embiando ahora por ellas para remitirlas me embia a desir su esposa, que anoche se desaparesio una de las muchachas y que estaba hasiendo las diligencias de ella por cuio motivo solo van quince entre hombres, mujeres y muchachos, quedando yo a hacer las diligencias para remitirla a V. Exa. luego que paresca.

Ntro. Sr. guarde la importante vida de V. Exa. los muchos años que deseo y e menester.

Tarma y Mayo 14 de 1746.

Queda a los pies de V. Exa.

Carlos Angulo y Cabrera

[Al margen: Lima y mayo 23 de 1746.

El Sr. Dn. Manuel Antonio de Borda pasará luego a la Real carzel de cortes y en el modo posible tomara las declaraciones a los indios contenidos en esta carta examinándolos sobre su estado y condizión origen y nacimiento como ansi mismo la ocupazión y destino en la que se hallaban al tiempo que los aprehendieron con todo lo demás que de sus respuestas resultare conveniente preguntarles para los efectos que en adelante hubiere lugar y fecho me remitirá las dilixencias.]

[f. 1v] Visto este Memorial y Decreto de su Exa. el escrivano Agustín de Portalanza en compañía de Su Merced y del ynterprete Gral. de los naturales de esta Real Audiencia pasaran a la Carsel de esta ciudad al efecto que se ordena poniéndose por cavesa de estos Autos este decreto:

Borda

Proveió y firmó el decreto de suso el Sr. Dn. Manuel Antonio de Borda, Alcalde del Crimen y Juez de Provincia de esta Real Audiencia en los Reies en veinte y tres de Maio de mil setecientos quarenta y seis.=

Ante mí,

Agustín Gerónimo de Portalanza 
[En la parte inferior, escrito transversalmente: Tarma, 13 y 14 de Mayo de 1746.

Dn. Carlos de Angulo y Cabrera

Remite con el cavo escuadra Eustaquio Lagar 15 Yndios, Yndias e Yndiesitos chunchos de los aprisionados en la entrada, que una se huyó y se handa buscando.

Da noticia del estado de la enfermedad del Sr. Llamas.]

[f. 2] [Al margen: Declaración de Francisco Solano Yndio, hedad 50 años Chuncho Christiano] Estando en la cárcel de la ciudad, en veinte y tres de maio de mil setecientos y quarenta y seis años, el Sr. Dn. Manuel Antonio de Borda, Alcalde del Crimen y Juez de Provincia de esta Real Audiencia en cumplimiento de lo proveido por su Exa. en día de la fecha a la carta escrita por D. Carlos de Angulo y Cabrera en que da quenta de la remisión que hace de quinse Yndios chunchos aprisionados en la entrada que se hiso a la Montaña, hiso compareser en su presencia a uno de ellos, a quien por medio de D. Joseph Caiotopa, Ynterprete General de los naturales de esta Real Audiencia, quien reiteró el juramento que hiso en la recepción de su empleo, en presencia de su merced y de este escrivano de desir e interpretar fiel y legalmente lo que se ordenase preguntar a dichos Yndios, y haviéndosele mandado preguntar al Yndio si sabía hablar castellano, dijo y respondió que no entiende la lengua española, y que solo abla la materna; preguntado si es christiano, respondió que sí, y que es baptisado muchos tiempos siendo de corta edad, por el P. Fr. Gerónimo misionero de la religión de N. P. S. Francisco y haviéndole hecho entender por medio de dicho interprete la gravedad y valor del juramento en lo que no deja de tener instrucción por desir y distinguir entre la verdad y mentira, su merced le hiso hacer juramento que lo hiso por Dios Ntro. Sr. y una señal de cruz según derecho, so cargo del qual prometió desir verdad, y siendo preguntado como se llama, dijo llamarse Francisco Solano Yndio, natural de Guancabamba, chuncho christiano que asi mismo lo fueron su Padre y Madre, quienes vivieron separados de los Yndios Aucas, que quiere desir Brabos, sujetos a la Religión y Padres Misioneros de N. P. S. Francisco; pregun- [f. 2v] tado que estado tiene dijo que es Viudo de Juana Petrona su muger que fue y que quien los casó fue el mismo P. Fr. Gerónimo que lo baptisó, y que su muger fue enterrada en la Yglesia que ai en el Pueblo de Guancabamba, que está al cuidado de los Religiosos de N. P. S. Francisco por el P. Fr. Matheo, y que de quatro años a esta parte no asisten en dicha Yglesia dichos Padres.

Preguntado en que se ocupaba como vivía de que comía, y con quienes se acompañaba dijo que se ocupaba en sembrar mais, llucas, camotes y arracachas, maní y otras legumbres, asi mismo Piñas y Cañas cuio fruto cogido después de tomar lo necesario para mantenerse, el resto vendía a los serranos de Tarma que están fuera de la Montaña sujetos al Corregidor de Tarma, que entran y salen y comercian con los christianos, como el declarante, y no pasan a la otra Banda del río donde están los Yndios Brabos que llaman Aucas. 
Preguntado si el Yndio Brabo lo tenía de espía para que les avisase o si de los frutos le llevava algunos, o él quería llevárselos, o les avisaría y participaba lo que pasava y comunicaban los Yndios serranos que entraban a comprarle.= Dijo que no servía de espía al Yndio Brabo, ni tampoco llevó frutos como se expresa ni quiso llevárselos, y que nunca los que entraban a donde el declarante le participaron nada ni él al Yndio por no saverlo y ser christiano.

Preguntado quienes son los Yndios serranos que entraban donde el declarante a comprarle los frutos, si los conoce y como se llaman, dijo que de los que dentraban a donde el declarante, aunque los conoce de vista solo save los nombres de Pasqual hijo de Narbaes mestizo buen hombre, que no sabe el nombre de Narbaes y solo si save que es Padre de dicho Pasqual y que dicho Narbaes es viejo, y Pasqual su hijo [ $f$. 3] moso, Arrieros que asisten en Carguamaio y Ninacaca, de la Provincia de Tarma.

Preguntado si ha pasado alguna vez donde dicho Arriero Narbaez a Ninacaca o Carguamaio, o si save aigan pasado otros, así de los Yndios moros, como de los christianos, o si estos tengan correspondencia con ellos, y si como entran donde el declarante pasan adentro donde los Yndios Aucas, dijo que el declarante y los Yndios christianos como él suelen a pasar a Ninacaca y Carguamaio y a otros pueblos de christianos como son Reies, Vico, y Pasco, Paucartambo, Quiparacra y otros que no save dar a entender sus nombres, y por lo que mira a si entran o no los dichos Yndios que comercian con el declarante donde los Aucas, que no entran ni los Aucas vienen donde ellos, ni tampoco los de los mencionados Pueblos pasan donde dichos Aucas.

Preguntado quien le señaló las tierras en que siembra y coge los frutos que lleva referidos, dijo que un Encomendero Español nombrado Vásquez que asistía en el Obrage de Paucartambo, que ahora no ai tal obrage, a hora muchos tiempos le señaló las tierras.

Preguntado en que se ocupaba y entretenía con los demás Yndios e Yndias, al tiempo que quando fueron aprehendidos por los soldados que los han traído a esta cárcel y si los demás Yndios e Yndias con quienes fue aprehendido son christianos o algunos de ellos Aucas, dijo que estando el declarante con los demás Yndios como a cosa de las sinco de la tarde en la Puerta de su Rancho, entre otros que ai vieron a los soldados quienes aguardaron a que anocheciese, y después de la orasión entraron y los aprehendieron, estando el declarante y los demás, unos hechados y durmiendo y otros sentados, y que entre ellos no ai Yndio Auca alguno porque todos son [f. 3v] Christianos, lo qual dijo vajo de juramento por vos del interprete, no supo desir su hedad, al pareser será de sinquenta años y que tiene una hija lejítima nombrada Juana Petrona que ha mantenido siempre consigo y vive alla en la carsel, que no tiene otros, no firmó por no saber, excutolo el dicho interprete y lo rrubricó su merced y de todo doi fée.= 
Ante mí,

Dn. Joseph Caiotopa Tito Athuchy Uscamayta

Agustín Gerónimo de Portalanza

[Al margen: Otra de Matheo Yndio hedad 35 años chuncho christiano] Y luego Yncontinenti en dicho día, mes y año dicho, prosiguiendo dicho señor en tomar declaraciones a los Yndios como se previene en el decreto de su Exa. hiso compareser a uno de ellos, de que por medio del interprete hiso preguntar si era christiano, respondió que sí y que lo havía baptisado de corta hedad el R. P. Fr. Matheo religioso misionero de N. P. San Francisco y haviendo dicho interprete por medio del presente escrivano quien le tomó el juramento dichole lo que contenía, dijo que lo savía, y juró por Dios Ntro. Señor y una señal de cruz según derecho desir verdad, y siendo preguntado como se llama, dijo en lengua castellana llamarse Matheo, ser casado con Petrona Yndia christiana y que el dicho P. Fr. Matheo los casó, así mismo dijo ser natural de Guancabamba Yndio christiano y que sus Padres lo fueron; que su muger se mantiene en Guancabamba también christiana de origen chuncho. [f. 4]

Preguntado en que se ocupava como vivía de que comía y con quienes se acompañaba, dijo que se ocupava en sembrar lluca de lo que se mantenía y que él solo vivía y no se acompañaba con nadie.

Preguntado si el Yndio Auca lo tenía de espía para que avisase lo que pasava entre los christianos, o si ha pasado él donde dicho Yndio o alguno de ellos donde él, dijo que no servía de espía alguno por no haver visto al Yndio, ni conocerlo ni saber nada de lo que pasava, y que no ha pasado ningún Yndio Auca donde el declarante, ni donde los christianos porque no los pueden ver.

Preguntado quien le dio las tierras en que sembraba, dijo que no save de quien eran ni quien se las dio porque travajava quando podía y que quando lo aprisionaron los soldados estaba en el Río pescando solo, y que haviéndolo aprehendido vio a los demás Yndios los ponían presos, los quales son christianos como el declarante y no Aucas, lo qual dijo ser la verdad vajo de juramento, no supo desir su hedad al pareser es de treinta y sinco años, que no tiene hijos, ni menos save quanto tiempo ha que es casado, no firmó por no saber, executolo el interprete rrubricolo su merced y de todo doi fée. $=$

Ante mí,

Dn. Joseph Caiotopa Tito Athuchy Uscamayta

Agustín Gerónimo de Portalanza

[f. 4v] [Al margen: Otra de María Bernarda Yndia 34 años hedad] Estando en la carsel de la ciudad en veinte y quatro de maio de mil setecientos quarenta y seis, prosiguiendo dicho señor Dn. Manuel Antonio de Borda, Alcalde de Crimen y Juez de Provincia de esta Real Audiencia, en tomar las declaraciones a los Yndios, 
como se previene en el decreto de su Exa. hiso compareser a una Yndia a la qual por medio del interprete le hiso preguntar si era christiana y si save ablar castellano, dijo ser christiana y que no save la lengua castellana, sí solo la materna y Quichua, y haviéndole hecho hacer el juramento y dadole a entender dicho interprete lo que contenía, dijo que jurava por Dios Ntro. Señor y una señal de cruz según derecho, y siendo preguntada como se llama, que estado tiene y de donde es natural, dijo llamarse María Bernarda y estar casada con Dn. Bernardo Tigsiguaina, curaca de Guancabamba, y natural de Guancabamba, y que su Marido es de dicho Guancabamba, y que es christiano muchos años ha y que los Baptisó y casó el R. P. Fr. Gerónimo, que no saven su apellido, solo sí que es Religioso misionero de N. P. San Francisco y que Petrona Margarita de hedad de quatro años es hija de la declarante y del dicho D. Bernardo, du Marido, a quien avrá quatro años mataron los Yndios Aucas en el Serro de la Sal, y que esta declarante se ha mantenido en dicho Pueblo de Guancabamba y que se ocupava en sembrar Mais, Llucas, Piñas, Maní y otras legumbres y que vivía en compañía de los que se allan presos, y de los demás que están en dicho su Pueblo, y que sacado de sus siembras para su mantención lo demás vende a los Mestizos y Españoles que dentran a dicho su Pueblo, y que de ellos conose a su compadre Nicolás Aiala de Paucartambo, a Diego Suárez Español de Quiparacra de la Provincia de Tarma, y que [f. 5] estos no trataban con los Yndios Aucas sino con los Christianos, como esta declarante, y que ni dichos Yndios vienen a su Pueblo, ni los del suyo van a los de dichos Yndios Aucas; y que quando estava esta declarante en Guancabamba un día como después de la orasión estando en su Rancho, entraron los soldados y la aprisionaron junto con los demás Yndios e Yndias, quienes son christianos como todos los demás que asisten en dicho su Pueblo, y no Aucas, quienes no le han dicho así a la declarante como a los de su Pueblo cosa alguna por no tener comunicación con ellos y no se le tomó declaración a su hija por no saver ablar y ser de la hedad dicha, lo qual dijo vajo juramento, no supo desir su hedad, al pareser será de treinta y quatro años, no firmó por no saber, executolo el Ynterprete, Rubicolo su Merced y a todo doi fée.=

Ante mí,

Dn. Joseph Caiotopa

Agustín Gerónimo de Portalanza

[Al margen: Otra de Petrona Viuda hedad 60 años Yndia chuncha christiana] Luego Yncontinenti en dicho día, mes y año dicho, prosiguiendo dicho señor en las expresadas diligencias, hiso compareser a una Yndia la qual por medio del interprete dijo ser christiana y baptisada por el R. P. Fr. Gerónimo, religioso misionero de San Francisco, y habiéndole hecho hacer el juramento y expresádole lo que contenía, dijo jurava por Dios Ntro. Señor y una señal de cruz según derecho y siendo preguntada que estado tiene, de donde es natural y como se llama, dijo llamarse Petrona, ser Viuda y natural de Guancabamba, y que [f. 5v] tiene un hijo que es el que se ha llevado al hospital enfermo, llamado Pedro Alcantara, y que esta declarante vivía en dicho Pueblo de Guancabamba con los que se allan presos y con otros de dicho 
su Pueblo y que se mantenía de lo que sembraba como es Mais, Maní y Piñas y que no vendía nada, y que los de su Pueblo ni ella tratan con los Aucas, ni ellos con los de dicho su Pueblo, por ser christianos, y que estando esta declarante con junto con los demás presos y otros como lleva dicho, estando en su Pueblo la aprisionaron los soldados, con los demás quienes son christianos y no Aucas, y que algunos Yndios serranos entran a dicho Pueblo de Guancabamba a quienes no conose esta declarante lo qual dijo vajo de juramento, no supo desir su hedad, al pareser será de sesenta años, no firmó por no saber, executolo el interprete, Rubicolo su merced y de todo doi fée. $=$

Ante mí,

Dn. Joseph Caiotopa Tito

Agustín Gerónimo de Portalanza

[Al margen: Auto] En atención a asentar Gerónimo Sans, Alcaide de la Carcel de la Ciudad, haberse pasado al Hospital de mi Señora Santa Ana uno de los Yndios que se condujeron a esta Ciudad de los que se aprehendieron en la Montaña, el presente escrivano, acompañado de su merced y [f. 6] Ynterpete General, que ha asistido a las antesedentes pasará a dicho Hospital, para que en él sea examinado el Yndio Pedro Alcantara.=

Proveiolo de suio decretado y rubicado el Sr. Dn. Manuel Antonio de Borda, Alcalde del Crimen y Juez de Provincia de esta Real Audiencia en los Reies en veinte y quatro de Maio de setecientos quarenta y seis.=

Ante mí,

Agustín Gerónimo de Portalanza

[Al margen: Otra de Pedro Alcántara enfermo en no 50 hedad 20 años chuncho christiano] Estando en el Hospital Real de mi Señora Santa Ana, en veinte y quatro de Maio de mil setecientos quarenta y seis, el Sr. Dn. Manuel Antonio de Borda, Alcalde del Crimen y Juez de Provincia de esta Real Audiencia, en cumplimiento de lo por su merced proveido en compañía del Ynterprete General de esta Real Audiencia le hiso preguntar a un Yndio de los conthenidos en el decreto de su Exa. el qual se alla enfermo en dicho Hospital, si era christiano y si savía ablar la lengua castellana y respondió que es christiano y que no save la lengua castellana por lo que dicho señor por medio del dicho interprete le expresó la gravedad del juramento y lo hiso por Dios Ntro. Señor y una señal de cruz según derecho, y siendo preguntado como se llama, que estado tiene y de donde es natural, dijo llamarse Pedro Alcantara, ser soltero y natural del Pueblo de Guancabamba, hijo lejitimo de Petrona, que se alla presa, y de su Padre no se acuerda por ser muerto y fue como el declarante y su Madre christiano y vivió separadamente de los Yndios Aucas y sujetos a los Religosos de N. P. San Francisco a cuio cargo esta la Yglesia de su Pueblo, y que [f. 6v] uno de dichos Religiosos nombrado Fr. Mathias fue quien baptisó a este declarante. 
Preguntado en que se ocupava, como vivía y con quienes se acompañaba, dijo que se ocupava en sembrar Lluca, Camote, Piña y demás legumbres y otros efectos, sacados los de su mantención, los demás vendía a los serranos que asisten fuera de la Montaña en el Pueblo de Tarma, que entran y salen a dicha Montaña, y solo tratan con los christianos como lo es el declarante, y no pasan a la otra Banda del Río, donde asisten los Yndios Aucas, con quienes no tienen trato así el declarante como los de su Pueblo por ser christianos, y que nunca ha visto al Yndio Auca, y que este no save se comunique con ningún serrano, pues en los que han ido a comprarle a este declarante sus frutos los conose de vista, pero no save el nombre de ninguno de ellos, y que como lleva dicho ninguno de estos pasa adonde el Auca, que es el Yndio Brabo, quien no puede ver a ningún Christiano; y que no se acuerda ni save quien le dio o señaló las tierras; y que estando un día que así mismo no se acuerda, como a hora de la orasión en el Pueblo de Guancabamba, en su Rancho, junto con Francisco Solano, Juana Petrona y demás que se allan en la carsel, entraron los soldados y los aprisionaron y que entre los que ai aquí, no ai ningún Yndio o Yndia Auca, sino todos christianos, todo lo qual dijo vajo del juramento que tiene hecho, por medio del interprete, y dijo ser de hedad de veinte años, no supo firmar, executolo el interprete, rubicolo su merced y de todo doi feé.=

\section{Dn. Joseph Caiotopa}

Agustín Gerónimo de Portalanza

[f. 7] [Al margen: Otra de María Josepha Viuda Yndia hedad 20 años chuncha christiana] Y luego Yncontinenti en dicho día, mes y año dicho, prosiguiendo dicho señor en haser las diligencias que se previenen en el decreto de su Exa. hiso compareser a una Yndia presa en la Carsel de esta Ciudad, la qual por medio del interprete fue preguntada si es christiana y así mismo si save la lengua castellana, y respondió es christiana y baptisada desde pequeña por el R. P. Fr. Matheo, religioso de N. P. S. Francisco y haviéndole dado a entender lo que contiene el juramento dicho señor por medio de dicho interprete y por ante mí el escrivano, le recivió juramento que lo hiso por Dios Ntro. Señor y una señal de cruz según derecho, y siendo preguntada que estado tiene, como se llama y de donde es natural, dijo llamarse María Josepha Viuda de Pablo Bentura, Yndio, quien murió avrá dos meses, y que es natural de Guancabamba, y que el dicho su Marido fue christiano y que quien los casó fue el P. Fr. Gerónimo de Ntro. P. San Francisco, quien asistía en dicho Pueblo de Guancabamba, donde residía esta declarante y en él vivía con los que se allan presos y otros de dicho su Pueblo, y se mantenía de las siembras que hasían de llucas, camotes, piñas y sapallos, los que vendían a los serranos de Carguamaio, que entran y salen a dicho su Pueblo, y que de ellos solo conose por su nombre a uno nombrado Visente que asiste en Sinchibilca, quien solamente tenía trato con esta declarante y sus compañeros por ser christianos, y que ninguno pasava a lo del Yndio Auca, ni de ellos adonde ninguno de su Pueblo; y que quando entraron en él los soldados que los aprisionaron, después de la orasión, estando recogidos en 
su Rancho junto con los de- [f. 7v] más que se allan presos, unos despiertos y otros durmiendo, y que los demás de su Pueblo no estaban aí y que ninguno de los que ai presos y están en su Pueblo son Aucas, sino christianos, y que la Yndiesita que será de hedad de quatro años nombrada Marthina Sebastiana, es hija legítima de la susodicha y su difunto Marido, la que por ser de corta hedad y no saver ablar, no examine, que según se alcansa por medio de dicho interprete, la dicha María Josepha dijo que todo lo que lleva dicho es la verdad, vajo de juramento que fecho tiene, no supo desir su hedad, al pareser será de veinte años, no firmó por no saber, executolo el interprete, rubicolo su merced y de todo doi feé.=

Ante mí,

Dn. Joseph Caiotopa Tito

Agustín Gerónimo de Portalanza

[Al margen: Otra de Juana Petrona Viuda de hedad de 20 años chuncha christiana] Y luego Yncontinenti en dicho día, mes y año dicho, prosiguiendo dicho señor en proseguir las diligencias que se contienen en el decreto de su Exa. hiso compareser a una Yndia a la qual por medio del interprete se le preguntó si era christiana y si savía la lengua castellana, lo que respondió que era christiana y que savía castellano [f. 8] lo que dicho interprete le expresó lo que contenía la religión del juramento y en su virtud su merced por ante mi el escrivano le recivió juramento que lo hiso por Dios Ntro. Señor y una señal de cruz según derecho, y siendo preguntada como se llama, que estado tiene y de donde es natural, dijo llamarse Juana Petrona, Viuda de Pedro Francisco, quien avrá que murió sinco meses, y era christiano, por haverlo baptisado así al dicho su Marido como a la declarante el R. P. Fr. Bernardo, del orden de Ntro. P. San Francisco y que quien los casó fue el R. P. Fr. Gerónimo religioso de dicha orden, quien residía en el Pueblo de Guancabamba de donde es natural, y que en lo que se ocupaba era en sembrar llucas, mais, maní y sapallos, y que esto lo executava en compañía de los demás por cuidarse unos a otros, y que sacado lo de su sustento, lo demás vendía a los de Carguamaio, a quienes conose de vista y no save sus nombres, y que estos no tratan mas que con la declarante y con los de su Pueblo por ser christianos, y no con los Aucas, porque estos no tratan con los de su Pueblo ni otra gente, ni los otros con ellos, y estando en su Pueblo y en su Rancho junto con sus compañeros entraron los soldados y los aprisionaron, sin que estuviesen hasiendo nada, $[f .8 v]$ y que ningún Yndio de su Pueblo ni de los presos son Gentiles, sino todos Christianos, todo lo qual dijo ser la verdad vajo del juramento fecho, vajo de el expresó que una muchacha nombrada María Dominga, que será de hedad de tres años es hija lejítima de la susodicha y del dicho su Marido, la que no declaró por su menor hedad y no saver ablar, no supo desir su hedad, al pareser será de diez y ocho a veinte años, no firmó por no saver, executolo el interprete, rubricolo su merced y de todo doi feé.= 
Ante mí,

Dn. Joseph Caiotopa Tito

Agustín Gerónimo de Portalanza

[Al margen: Otra de Juana Narsisa Yndia casada hedad 18 años chuncha christiana] Y luego Yncontinenti en dicho día, mes y año dicho, prosiguiendo dicho señor en tomar las declaraciones por medio del interprete General de los naturales de esta Real Audiencia, hiso compareser a una Yndia, la qual preguntada como se llama, si es Christiana y si save la lengua castellana, respondió ser christiana y que la havía baptisado el R. P. Fr. Matheo del orden de Ntro. P. San Francisco y que no save la lengua castellana por lo qual su merced por ante mi el escrivano hiso que el interprete le expresase lo que contenía la religión del juramento, el que hiso por Dios Ntro. Señor y una señal de cruz según derecho, y siendo preguntada que estado tiene y donde es natural, dijo llamarse Juana Narsisa casada con Francisco, y natural [f. 9] del Pueblo de Guancabamba y que quien los casó fue el R. P. Fr. Matheo, quien residía en dicho Pueblo, y que en él se ocupava en sembrar llucas, camotes, piñas y sapallos y que sacado con lo que se mantenía lo demás vendía a los Arrieros Serranos de Carguamaio y Ninacaca, a quienes conose de vista y no save sus nombres y que estos solo tratan con la declarante y los de su Pueblo por ser christianos, y no con los Yndios de Aucas porque estos no pasan de la Banda del Río para aca, y así save que ninguno trata con ellos, ni ellos con ninguno de parte alguna ni de su Pueblo, y estando en él un día que no se acuerda como a voca de la orasión un poco más en compañía de su Madre María Josepha que se alla en dicho Pueblo, y Juana Espíritu Santo, presa en la carsel, su hermana, entraron los soldados, y las aprisionaron, y que todo lo que lleva dicho es la verdad, vajo del juramento y así mismo expresó que una muchacha que será de hedad de quinse días que parió en el camino quando la traheron, nombrada María Encarnasión, es hija de la susodicha y de su Marido, no supo desir su hedad, será de diez y ocho años al pareser, no firmó por no saver, executolo el interprete, rubricolo su merced y de todo doi feé.=

Dn. Joseph Caiotopa Tito

Agustín Gerónimo de Portalanza

[f. 9v] [Al margen: Otra de María Dominga Asencio casada Yndia hedad 17 años] Y luego Yncontinenti en dicho día, prosiguiendo dicho señor en las diligencias que se previenen en el decreto de su Exa. hiso comparecer en su presencia a una Yndia, la qual preguntada si es christiana y si save la lengua castellana, dijo ser christiana y haverla baptisado el P. Fr. Antonio religioso de Ntro. P. San Francisco y que no save la lengua castellana por cuio motivo su merced hiso al interprete le expresase lo que contenía la religión del juramento, el qual hiso por Dios Ntro. Señor y una señal de cruz según derecho, y siendo preguntada como se llama, que estado tiene y de donde es natural, dijo llamarse María Dominga Asencio, casada con Simón christiano, y que los casó el P. Arevalo de San Francisco y natural de Guancabamba, donde residía y vivía con su Madre nombrada María Rosa y se 
ocupava en sembrar llucas, Papas, camotes en compañía de la dicha su Madre que se alla en Guancabamba y de las demás de dicho Pueblo, y que sacado su mantención lo demás vendía a los del Pueblo de Reies, que uno de ellos era tío suio, y los demás no conose, y otros de Tarma, quienes trataban con esta declarante y los de su Pueblo por ser Christianos, y que estos no tratan con los Yndios Aucas, ni estos con ellos [f. 10] por no poder ver a los Christianos, ni a los de su Pueblo, y que estando en él un día, poco después de la orasión, en sus Ranchos juntos con los que se allan presos, y el dicho su Marido que se fue, entraron los soldados y los aprisionaron, y trajeron a esta Ciudad, y que todos los que se allan aquí y los de su Pueblo son todos Christianos, todo lo qual dijo vajo de juramento, no supo desir su hedad al pareser será de diez y siete años, no firmó por no saver, executolo el interprete, rubricolo su merced y de todo doi feé. $=$

Ante mí,

Dn. Joseph Caiotopa Tito

Agustín Gerónimo de Portalanza

[Al margen: Otra de María Ysavel donsella hedad de 7 o 8 años] Y luego Yncontinenti en dicho día, dicho señor prosiguiendo en las diligencias que se contienen en el decreto de su Exa. hiso comparecer a una Yndia la qual fue preguntada si es christiana y si save la lengua castellana, dijo ser christiana y haverla baptisado el R. P. Fr. Matheo religioso de Ntro. P. S. Francisco por lo qual su merced le expresó al interprete le significase la gravedad del juramento, el qual hiso por Dios Ntro. Señor y una señal de cruz, y siendo preguntada como se llama, que estado tiene y de donde es natural, dijo llamarse María Ysavel, doncella [f. 10v] natural de Guancabamba, hija de Juana Petrona, que se alla presa en esta carsel, y que no se acuerda como se llama su Padre, el qual es muerto, quien era de dicho Pueblo, y que en lo que se ocupava esta declarante era en quitar las malas hierbas de las plantas y limpiar llucas, y preguntadosele si conosía al Yndio Auca, dijo que no como así mismo otras preguntas que se le hisieron, a las que no save dar rrason, por cuio motivo se dejó en este estado, lo qual dijo vajo de juramento, no supo desir su hedad, al pareser será de siete a ocho años, no firmó por no saver, rubricolo su merced y de todo doi feé.=

Ante mí,

Dn. Joseph Caiotopa Tito

Agustín Gerónimo de Portalanza

Y luego Yncontinenti en dicho día, mes y año, dicho señor, prosiguiendo en las diligencias que se contienen en el decreto de su Exa. hiso comparecer a una muchacha, la qual preguntada si era Christiana, respondió que si, y que la baptiso el R. P. Fray Matheo de San Francisco, a la qual haviéndosele hecho varias preguntas, solo dice que es christiana y que es hija de María Josepha, presa en esta carsel, y llamarse María Espíritu, y que será al pareser de seis años, lo firmó el interprete y su merced lo rubricó y de todo doi feé.= 
Ante mí,

Dn. Joseph Caiotopa Tito

Agustín Gerónimo de Portalanza

[f. 11] Lima y Mayo 25 de 1746.

En atención a que por las diligencias actuadas y declaraciones de los quinze Yndios de todos sexos y edades que remitió Dn. Carlos Angulo de orden del Sr. Marqués de Menahermosa desde la Provincia de Tarma a esta Real Carcel de Corte no resulta culpa ni cargo de haver comunicado o comerciado con el Yndio rebelde, ni servido de espías, o ministrádole algunos frutos; serán sueltos de la prisión en que se hallan y por ello se entregarán al P. Fr. Joseph de San Antonio, Comisario de las Miciones del Serro de la Sal; y que los haga poner y distribuya en los Pueblos y Paraxes en que puedan ser mas bien educados e instruidos en Ntra. S. Feé Catholica, especialmente los Yndiecitos e Yndiecitas de tierna edad, sin que se expongan a peligro de comunicación con los Ynfieles, dándome quenta dicho P. Fr. Joseph de la distribución que hiciere, lugares y Pueblos donde los pusiere.=

[f. 11v] [Al margen en la parte inferior derecha transversalmente: Autos de Yndios chunchos remitidos por el Gral. Marqués de Menahermosa] 